\author{
Mediterranean BioMedical Journals \\ Integrative Journal of Medical Sciences \\ 2020, Volume 7, ID 192 \\ DOI: $\underline{10.15342 / \mathrm{ijms.7.192}}$
}

CLINICAL STUDY

\title{
Radiographic Assessment of the Quality of Post \& Core Restorations Performed by Dental Students at Qassim University Dental Clinics
}

\author{
Abdullah Refai Almutairi ${ }^{1}$, Mohammed Ibrahim Mathar ${ }^{2}$ \\ ${ }^{1}$ College of Dentistry in Ar Rass, Qassim University, Kingdom of Saudi Arabia (KSA). \\ ${ }^{2}$ Department of Prosthodontic Sciences, College of Dentistry in Ar Rass, Qassim University, Kingdom of Saudi Arabia (KSA).
}

\begin{abstract}
Introduction: A post usually made of prefabricated or custom made that is fitted into a prepared root canal of a natural tooth. Core is the foundation restoration which restores adequate coronal anatomy of a vital or endodontically treated tooth. When the post is combined with a core, it provides retention and resistance for an artificial crown. The primary purpose of the post is to retain a core restoration and crown, and also to redistribute the stresses onto the root, thereby diminishes the risk of coronal fracture. The post does not have any role in reinforcing or supporting the tooth. The aim of the study was to assess the quality of the post and core restorations with postoperative periapical digital radiographs performed by undergraduate students at the College of Dentistry, Qassim University.

Materials and methods: A total of 421 periapical digital radiographs were assessed. The assessment includes the type of tooth, type of arch, type of post, length of post, the presence of any abnormality in post space, status of the remaining guttapercha (GP), and if there is any spaces between the end of post and GP. Data were analyzed using the Statistical Package for the Social Sciences (SPSS) program (version 23).

Results: Maxillary teeth were the most frequently restored teeth with post (67.2\%) and majority of the cases were comprised of premolars $(57.2 \%)$. Similarly, glass fiber post $(89.1 \%)$ with taper shaped were the most widely used post. The majority of the post featured a width of one-third of the root (81\%). Length of the post with crown: post ratio of 1:3 was observed as the most frequently used (60.8\%), whereas those of post length with crown: post ratio of 1:2 (25.4\%) and 1:1 post length was least frequently used (13.8\%). $28 \%$ of cases were presented with 3 to $5 \mathrm{~mm}$ of GP at their apical portion and $61.5 \%$ cases reached more than $5 \mathrm{~mm}$. Approximately 5 to $8 \%$ of assessed cases revealed the widening of the periodontal ligaments.

Conclusion: The performance of students was assessed by the quality of different types of post and core restorations with the postoperative periapical digital radiographs. The qualities of assessed post and core restorations prepared by the dental students were clinically acceptable.
\end{abstract}

KEYWORDS: Dental Students, Ferrule, Fixed Prosthesis, Periapical Radiograph, Post and Core Restorations.

Correspondence: Dr Mohammed Ibrahim Mathar, M.D.S., Assistant Professor, Department of Prosthodontic Sciences, College of Dentistry in Ar Rass, Ar Rass - 51921, Kingdom of Saudi Arabia (KSA).

Email id: dr.mohammed.mathar@qudent.org

Copyright (C) 2020 Almutairi AR \& Mathar MI. This is an open access article distributed under the Creative Commons Attribution 4.0 International, which permits unrestricted use, distribution, and reproduction in any medium, provided the original work is properly cited.

\section{INTRODUCTION}

Post and core are mostly used to restore endodontically treated teeth with extensive loss of tooth structure ${ }^{1}$. Usually, post and core failures have been known as one of the most common causes of failure in endodontically treated teeth ${ }^{2}$. Post and core was one of the most important procedure in dental clinic. In the College of Dentistry at Qassim University, as part of the requirements in dental practice course and preclinical lab, all students must complete certain number of post and core in the lab and also in the clinic . 
Results of post and core restorations in the prosthetic treatment plan depend upon the proper diagnosis and treatment planning and each phase of that plan to be delivered perfectly. Hence, the assessment must be performed as follows as before post insertion, checking of root canal treatment (RCT) system seal, after cementation, during follow-up after teeth exposed to masticatory loading forces, and monitoring during maintenance recall to evaluate the treatment method $^{3,4}$.

Typically, a correlation exists between preclinical performance on phantom lab on a typhodont and clinical performance on patients which is relevant to the preparation of post and core restorations by dental students ${ }^{5}$. Thus, dental graduates should develop optimum skills through well supervised preclinical and clinical trainings ${ }^{6}$. The knowledge and skills of graduates should be assessed periodically by the effectiveness of teaching strategies ${ }^{7}$.

\section{MATERIALS AND METHODS}

This cross-sectional study was approved by the Dental Ethics Committee, College of Dentistry, Qassim University code : DRC/008In/6-20. Consent form was taken from all the patients in this study. Post fabricated by Qassim University dental students were included in this study based on the data base in college of Dentistry. The following datas were considered as evaluation parameters:

- Arch and type of tooth involved.

- Post type: Glass fiber post (GFP), custom-made post (CP), and prefabricated metal post and post width in relation to root diameter.

- Post length in relation to crown and root length.

- Radiographic condition of the remaining GP: 3 to 5 $\mathrm{mm}$-extruded, unacceptable or condensed or more than $5 \mathrm{~mm}$ at the apex.

- Presence or absence of space between the end of post and GP.

The inclusion criteria are:

- Patients aged more than 18 years from both the genders.

- Properly restored root canal treated tooth.

The following cases were excluded:

- Cases with incomplete root formation.

- Cases of retreated RCT.

- Improper radiographic images.

- Previous surgical procedures such as cyst enucleation or apicectomy.

- Cases without a post-obturation radiograph either with temporary or permanent restoration was placed.

Then, the datas were summarized as frequencies and percentages. All statistical analyses were performed using SPSS software (version 23, SPSS, Chicago, Illinois, USA).

\section{RESULTS}

A total of 421 Digital periapical X-ray were included in this study. Digital periapical X-ray was assessed among the mentioned subjects.
- According to the type of arch, the highest frequency was observed in the maxillary arch $(\mathrm{n}=283,67.2 \%)$ followed by the mandibular arch $(n=138,32.8 \%)$.

- Based on the type of tooth involved, premolar teeth were the most frequently restored with post $(\mathrm{n}=241$, $57.2 \%)$, followed by incisor $(\mathrm{n}=97,23 \%)$ and molars $(n=60,14.3 \%)$. Canines were the least restored teeth $(n=23,5.5 \%)$ with post.

- Based on the type of post, glass fiber post were significantly detected among patients $(n=375$, $89.1 \%$ ) compared with custom made post $(\mathrm{n}=27$, $6.4 \%$ ), whereas metal prefabricated post were the least frequent $(\mathrm{n}=19,4.5 \%)$.

- The most frequently used posts yielded a width of $1 / 3$ $(\mathrm{n}=341,81 \%)$, followed by $1 / 2 \quad(\mathrm{n}=59,14 \%)$ then followed by $1 / 1(n=21,5 \%)$.

- Post length with a crown :post ratio of 1:3 was observed as the most frequently used $(n=256$, $60.8 \%$ ), whereas those of post length with

- crown :post ratio of 1:2 $(\mathrm{n}=107,25.4 \%)$. A crown : post ratio of 1:1 post length was observed as the least frequently used $(\mathrm{n}=58,13.8 \%)$.

- Regarding the condition of remaining GP in relation to post, the majority of cases $(n=259,61.5 \%)$ showed more than $5 \mathrm{~mm}$ of GP apical to the end of post. A total of 118 cases (28\%) featured 3 to $5 \mathrm{~mm}$ of GP apical to the post end. About 31 cases (7.4\%) showed unsatisfactory condensation of GP, whereas 13 cases (3.1\%) showed extrusion of GP beyond the apex.

Graph 1 represents the relationships between space at the post end and GP. The majority of cases (349) showed the absence of space $(82.9 \%)$. A total of $72(17.1 \%)$ cases revealed the presence of space between post and GP.

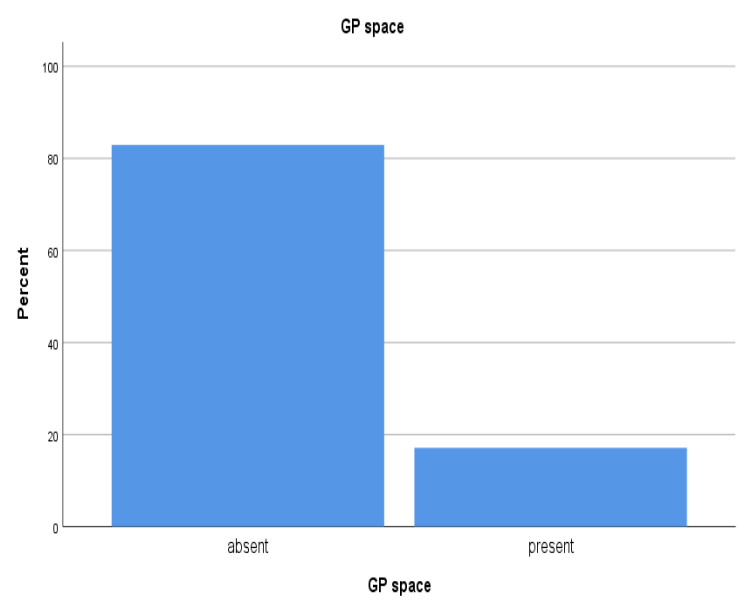

Graph 1: GP space Vs Post end

\section{DISCUSSION}

The endodontically treated tooth supported with post and core was considered as a common procedure in dental practice. Many criteria have been suggested to assess the quality of post and core restorations. The majority of these criteria are based mainly on radiographic evaluation alone or in combination with clinical examination ${ }^{8,9}$. 
Results of the present study revealed that posts are more frequently used in maxillary arch than in mandibular arch (Table1). These results support some previously reported findings by Jamani et $\mathrm{al}^{10}$ and $\mathrm{Al}-\mathrm{Hamad}$ et $\mathrm{al}^{12}$ that the most frequently restored teeth with post and core were maxillary arch (Table 1).

According to the findings of the present study, canines in both arches are the least frequently restored teeth with post $^{12.13}$ and this finding indicates the reluctance of dentists to save badly destroyed canines because of their position at the angle of the arch to establish canine guidance occlusion. In general, canine teeth are the least frequently root canal treated teeth. In our study, percentages of post in premolars were the most restored tooth (Table 1). However, Jamani et $\mathrm{al}^{10}$ reported that mandibular teeth are the least frequently retained by posts. On the contrary, Al Subait et $\mathrm{al}^{11}$ discovered that posterior maxillary and mandibular teeth are the most frequently retained by post $(73.6 \%)$. Such differences indicate that esthetics (incisors) and functions (molars) are the important motivating factors for the dental treatment.

Table 1: Overall parameters of frequency and percentage in relation to arch, type of tooth, type of post, post length, post width and the condition of GP.

\begin{tabular}{|c|c|c|c|}
\hline \multicolumn{2}{|l|}{ Parameters } & Frequency (n) & Percentage (\%) \\
\hline \multirow{3}{*}{ Arch } & Maxillary & 283 & 67.2 \\
\hline & Mandibular & 138 & 32.8 \\
\hline & Total & 421 & 100 \\
\hline \multirow{5}{*}{ Type of tooth } & Canine & 23 & 5.5 \\
\hline & Incisor & 97 & 23.0 \\
\hline & Molar & 60 & 14.3 \\
\hline & Premolar & 241 & 57.2 \\
\hline & Total & 421 & 100 \\
\hline \multirow{4}{*}{ Type of post } & Custom made post & 27 & 6.4 \\
\hline & Glass fiber post & 375 & 89.1 \\
\hline & Metal prefabricated post & 19 & 4.5 \\
\hline & Total & 421 & 100 \\
\hline \multirow{4}{*}{ Post length } & $1: 1$ & 58 & 13.8 \\
\hline & $1: 2$ & 107 & 25.4 \\
\hline & $1: 3$ & 256 & 60.8 \\
\hline & Total & 421 & 100 \\
\hline \multirow{4}{*}{ Post width } & $1: 1$ & 21 & 5 \\
\hline & $1: 2$ & 59 & 14 \\
\hline & $1: 3$ & 341 & 81 \\
\hline & Total & 421 & 100 \\
\hline \multirow{5}{*}{ GP condition } & from 3 to $5 \mathrm{~mm}$ & 118 & 28.0 \\
\hline & more than $5 \mathrm{~mm}$ & 259 & 61.5 \\
\hline & over filling & 13 & 3.1 \\
\hline & unacceptable & 31 & 7.4 \\
\hline & Total & 421 & 100 \\
\hline
\end{tabular}

The diameter of clinically acceptable posts should be one-third to that of $\operatorname{root}^{13,14}$. The most frequent post width found in the present study measured one-third to that of root was $81 \%$ as shown in Table 1, whereas the rest were too thin or too thick. This result can be explained by the lack in experience of some newly graduated dentists in preparing root canals for post reception.

In the present study, GFP was used in the majority of cases $(89.1 \%)$, whereas CP and prefabricated metal post were used in 6.4 and $4.5 \%$ of cases respectively (Table 1). Such findings have already been revealed by the results of Nimigean et $\mathrm{al}^{13}$ stated that $\mathrm{CP}$ accounted for $69.6 \%$ of included cases. However, in our study, incidence rate $(6.4 \%)$ of prefabricated metallic posts was less compared with that of the above previous study. Studies have depicted that GFP possesses physical properties such as modulus of elasticity was similar to that of natural dentine ${ }^{13,14}$. Therefore, most studies have recommended the wide use of GFP whenever possible.

Ideally, post length should be as long as possible, but without jeopardizing the apical seal or strength and integration of remaining roots ${ }^{11}$.

In cases of GFP, its length should not be shorter than or equal to clinical crown length. In addition, an optimal ferrule should be present to resist the vertical of the $\operatorname{root}^{15}$. McComb ${ }^{15}$ recommended that post length should be half the root length, midway between the apex and alveolar crest and should leave a space of $4-5 \mathrm{~mm}$ for GP at the apex. In this study, a 1:3 ratio of post crown :length was identified in $60.8 \%$ of cases (Table 1), similar to that was reported by Al-Hamad et al ${ }^{11}$. A 1:2 ratio of crown :length reached $25.4 \%$ of the cases in the present study (Table 1) opposite to that was reported by Al-Hamad et $\mathrm{al}^{12}$. The findings in this present study are better compared with those reported by Jamani et $\mathrm{al}^{10}$ and 
Nimigean et $\mathrm{al}^{13}$. This observation can be attributed to the effectiveness of methods used in post preparations, especially for GFP. The proportion of $13.8 \%$ of post cases in this study was within the acceptable range because it features a 1:1 ratio of post length :crown length coinciding with the studies reported by McLean ${ }^{16}$ who emphasized that post length within root canals should be at least equal to crown height.

Regarding the RCT, the length of remaining GP that needs to be placed at the left apical of the end of posts, to maintain apical integrity and proper apical seal, should range from 3 to $4 \mathrm{~mm}$ or 3 to $5 \mathrm{~mm}^{10,11,14}$. In this present study, $61.5 \%$ of assessed endodontically treated teeth featured more than $5 \mathrm{~mm}$ of GP and $28 \%$ presented 3- 5 $\mathrm{mm}$. This result can be considered as excellent feature, especially $89.1 \%$ of cases were restored with $\mathrm{GFP}^{15}$. This percentage was higher than the $70.7 \%$ observed among posts evaluated by Jamani et $\mathrm{al}^{10}$. This result may be related to other factors including root-crown ratio, crown length, and amount of ferrule left rather than the amount of GP left to avoid jeopardizing the GP seal.

Regarding condensation and density of the remaining GPs, $7.4 \%$ of included cases were exhibited poor density, which was in contrast with findings of studies by Smadi et $\mathrm{al}^{9}$. The majority of cases in the present study showed no spaces between post end and GP (Graph 1). The above observation clearly depicts that the student who performed RCT was also the one who proceeded with post space preparation and were the most knowledgeable regarding the presence of the area of root curvatures and

\section{REFERENCES}

[1] Sorrentino R, Di Mauro MI, Ferrari M, Leone R, Zarone F. Complications of endodontically treated teeth restored with fiber posts and single crowns or fixed dental prostheses - a systematic review. Clin Oral Investig. 2016 Sep 26;20(7):1449-57. DOI: $10.1007 / \mathrm{s} 00784-016-1919-8$

[2] Guldener KA, Lanzrein CL, Siegrist Guldener BE, Lang NP, Ramseier CA, Salvi GE. Long-term Clinical Outcomes of Endodontically Treated Teeth Restored with or without Fiber Post-retained Single-unit Restorations. J Endod. 2017 Feb 1;43(2):188-93. DOI: $10.1016 /$ j.joen.2016.10.008

[3] Bajawi AM, AL-Sagoor SA, Alhadi AA, Alhadi MA, Almasrahi MY, AL-Ghazali N, Al-Moaleem MM. Radiographic Assessment of the Quality of Root Canal Treatments Performed by Practitioners with Different Levels of Experience. Biomed Pharmacol J. 2018;11( 3):1609-16. DOI $: \underline{10.13005 / \mathrm{bpj} / 1528}$

[4] Reis N, Bergamini M, Silvestre T, Veitz-Keenan A. Are fibre posts associated with the occurrence of prosthetic complications? Evid Based Dent. 2018 Jun 22;19(2):62. DOI: 10.1038/sj.ebd.6401313

[5] Chakravarthy PK, Moorthy JK. Radiographic assessment of quality of root fillings performed by undergraduate students in a Malaysian Dental further apical preparations. Up to $17.1 \%$ of cases were presented with spaces between post and GP, this result was close to the $22.2 \%$ obtained by Al-Hamad et al ${ }^{11}$.

\section{CONCLUSION}

Within the limitations of the present study, the following can be concluded:

- Post-retained crown designs achieved in the majority of cases were acceptable and close to ideal design characteristics.

- The most frequent restored tooth is premolar and the most frequent arch is maxillary arch

- The GFPs were the most frequently used post types, followed by CPs and prefabricated ready-made metallic posts.

- The majority of posts measured one-third of the root width and equal to or twice the length of crowns or roots of restored teeth.

- The majority of post cases featured more than $5 \mathrm{~mm}$ of GP at their apex and $28 \%$ between 3 and $5 \mathrm{~mm}$.

The present study was focused on the performances of the undergraduate students in Dental College, Qassim University. Hence, students performance was assessed by the quality of different types of cemented post and core with postoperative periapical digital radiographs.

\section{COMPETING INTERESTS}

The authors declare no competing interests with this study.
School. Saudi Endod J. 2013;3(2):77-81. DOI: $10.4103 / 1658-5984.118155$

[6] Hunter AJ, Flood AM. The restoration of endodontically treated teeth. Part 2. Posts. Aust Dent J. 1989 Feb;34(1):5-12. DOI: 10.1111/j.18347819.1989.tb02998.x

[7] Cagidiaco MC, Goracci C, Garcia-Godoy F, Ferrari M. Clinical studies of fiber posts: a literature review. Int J Prosthodont. 21(4):328-36.

[8] Ferrari M, Vichi A, Fadda GM, Cagidiaco MC, Tay FR, Breschi L, et al. A Randomized Controlled Trial of Endodontically Treated and Restored Premolars. J Dent Res. 2012;91(7 Suppl):S72-8. DOI: $\underline{10.1177 / 0022034512447949}$

[9] Naumann M, Koelpin M, Beuer F, Meyer-Lueckel H. 10-year Survival Evaluation for Glass-fibersupported Postendodontic Restoration: A Prospective Observational Clinical Study. J Endod. 2012 Apr;38(4):432-5. DOI: $10.1016 /$ j.joen.2012.01.003

[10] Jamani KD, Aqrabawi J, Fayyad MA. A radiographic study of the relationship between technical quality of coronoradicular posts and periapical status in a Jordanian population. J Oral Sci. 2005;47(3):123-8. 
[11] Al Subait A, Albawardi A, Alghomlas A, Daabash M, Alotaibi M, Alturki Y. Success and Survival Rates of Teeth Restored With Cast Post and Core among National Guard Health Affairs Patients, Riyadh, Saudi Arabia. Adv Dent Oral Heal. 2016;2(2).

DOI:

$\underline{\text { 110.19080/ADOH.2016.01.555583 }}$

[12] Al-Hamad KQ, Al-Omari M, Al-Wahadni A, Darwazeh A. Radiographic assessment of postretained crowns in an adult Jordanian population. J Contemp Dent Pract. 2006 Sep 1;7(4):029-36.

[13] Nimigean VR, Buţincu L, Nimigean V. A radiographic study regarding post retained restorations. Rom J Morphol Embryol. 2012;53(3 SUPPL.):775-9.

[14] Adanir N, Belli S. Evaluation of different post lengths' effect on fracture resistance of a glass fiber post system. Eur J Dent. 2008 Jan;2(1):23-8.

[15] McComb D. Ensuring continued trust. Restoration of the endodontically treated teeth. London: Quintessence; 2008.pp. 1-19.

[16] McLean A. Predictably restoring endodontically treated teeth. J Can Dent Assoc. 1998 Dec;64(11):782-7. 